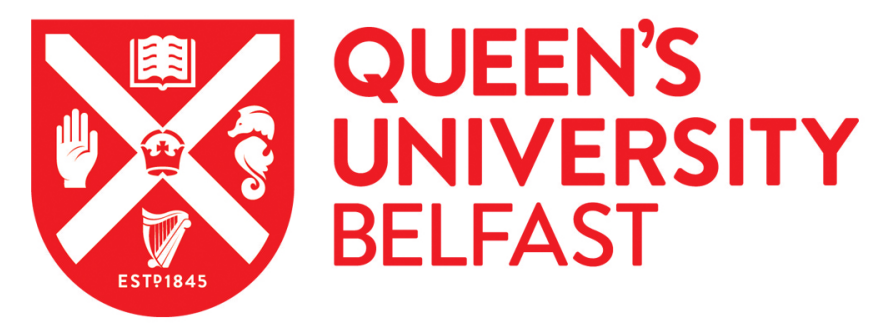

\title{
A concept analysis of renal supportive care: the changing world of nephrology
}

Noble, H., Kelly, D., Rawlings-Anderson, K., \& Meyer, J. (2007). A concept analysis of renal supportive care: the changing world of nephrology. Journal of Advanced Nursing, 59(6), 644-653. https://doi.org/10.1111/j.13642648.2007.04383.x

Published in:

Journal of Advanced Nursing

Document Version:

Peer reviewed version

Queen's University Belfast - Research Portal:

Link to publication record in Queen's University Belfast Research Portal

\section{General rights}

Copyright for the publications made accessible via the Queen's University Belfast Research Portal is retained by the author(s) and / or other copyright owners and it is a condition of accessing these publications that users recognise and abide by the legal requirements associated with these rights.

Take down policy

The Research Portal is Queen's institutional repository that provides access to Queen's research output. Every effort has been made to ensure that content in the Research Portal does not infringe any person's rights, or applicable UK laws. If you discover content in the Research Portal that you believe breaches copyright or violates any law, please contact openaccess@qub.ac.uk. 


\title{
JAN THEORETICAL PAPER
}

\section{A concept analysis of renal supportive care: the changing world of nephrology}

\author{
Helen Noble, Daniel Kelly, Karen Rawlings-Anderson \& Julienne Meyer
}

Accepted for publication 23 May 2007

Correspondence to H. Noble:

e-mail: H.R.Noble@city.ac.uk

Helen Noble BSc RN DMS

Doctoral Student

Care for Older Adults Research Team, St Bartholomew School of Nursing \&

Midwifery, City University, London, UK

Daniel Kelly PhD RN

Reader in Cancer \& Palliative Care

School of Health \& Social Sciences,

Middlesex University, London, UK

Karen Rawlings-Anderson MSc RN DipN Ed

Senior Lecturer/MSc Nursing Programme

Director

Department of Adult Nursing,

St Bartholomew School of Nursing and

Midwifery, City University, London, UK

Julienne Meyer BSc MSc PhD RN RNT Professor of Nursing: Care for Older People St Bartholomew School of Nursing and Midwifery, Institute of Health Science, City University, London, UK

NOBLE H., KELlY D., RAWLINGS-ANDERSON K. \& MEYER J. (2007) A concept analysis of renal supportive care: the changing world of nephrology. Journal of Advanced Nursing 59(6), 644-653

doi: 10.1111/j.1365-2648.2007.04383.x

\begin{abstract}
Title. A concept analysis of renal supportive care: the changing world of nephrology Aim. This paper is a report of a concept analysis of renal supportive care.

Background. Approximately 1.5 million people worldwide are kept alive by renal dialysis. As services are required to support patients who decide not to start or to withdraw from dialysis, the term renal supportive care is emerging. Being similar to the terms palliative care, end-of-life care, terminal care and conservative management, there is a need for conceptual clarity.

Method. Rodgers' evolutionary method was used as the organizing framework for this concept analysis. Data were collected from a review of CINAHL, Medline, PsycINFO, British Nursing Index, International Bibliography of the Social Sciences and ASSIA (1806-2006) using, 'renal' and 'supportive care' as keywords. All articles with an abstract were considered. The World Wide Web was also searched in English utilizing the phrase 'renal supportive care'.

Results. Five attributes of renal supportive care were identified: available from diagnosis to death with an emphasis on honesty regarding prognosis and impact of disease; interdisciplinary approach to care; restorative care; family and carer support and effective, lucid communication to ensure informed choice and clear lines of decision-making.

Conclusion. Renal supportive care is a dynamic and emerging concept relevant, but not limited to, the end phase of life. It suggests a central philosophy underpinning renal service development that allows patients, carers and the multidisciplinary team time to work together to realize complex goals. It has relevance for the renal community and is likely to be integrated increasingly into everyday nephrology practice.
\end{abstract}

Keywords: concept analysis, death and dying, dialysis, palliative care, renal nursing, supportive care

\section{Introduction}

Recently there have been dramatic changes in the demography and long-term management of patients with end-stage renal disease (ESRD) (Smith et al. 2003). The number of patients treated for terminal renal failure has grown at a rate that is in excess of the growth rate of the general population (Grassman et al. 2005). Today there are approximately 1.5 
million patients around the world receiving dialysis alone and the numbers are growing at an annual average of $7 \%$ in those privileged populations that have access to such treatment (ISN and IFKF 2007).

In the United Kingdom (UK), it has been established that the numbers of patients receiving dialysis are increasing by approximately $10 \%$ per annum (Ansell et al. 2005). This includes disproportionate numbers of those who are older, frailer and more dependent. Older people with ESRD also have increasing prevalence of co-morbidities such as diabetes and heart disease (Ashby et al. 2005). It is known that patients with ESRD are at higher risk of dying than the general population, with a median risk between one-third and one-sixth as long as non-dialysis patients of the same age and sex (Cohen et al. 2006). Unless lucky enough to receive a successful transplant, being told that one has terminal renal failure requiring dialysis involves the communication of 'bad' or 'significant' news with similar resonance to a diagnosis of cancer (Arnold \& Solomon 2006). However, this is seldom acknowledged. It is becoming more evident that a seamless structure of supportive care is needed as renal patients embark on their journey from diagnosis to death.

\section{Background}

The first author has recently been involved in helping to establish a new Supportive Care Service for renal patients who have declined, or decided to withdraw from, dialysis treatment and face the likelihood of imminent death. Similar services are being developed nationally in the UK. In particular, the National Service Framework (NSF) for Renal Services: Part 2 (DOH 2005) includes a specific section on end-of-life care and refers to the need to combine palliative care and renal skills to develop and provide services. It considers the requirement for palliative care interventions when patients decide to stop dialysis and at the end of life, but makes no reference to supportive or palliative care at an earlier stage. Although it has been known for some time that renal patients have shortened life expectancy and many carry a high symptom burden (Cohen et al. 2006, Murtagh et al. 2006, Saini et al. 2006), the NSF does not mention the involvement of palliative and supportive care teams through the dialysis trajectory. Although there is some uncertainty about how the role of the Renal Supportive Care Service will evolve, it is appropriate that terminology is clarified so that clear goals can be agreed. A future aim of the service is to integrate the principles and practice of palliative care into other areas of the renal unit, namely the haemodialysis, peritoneal dialysis and, where necessary, the transplant population to ensure that all renal patients with limited life expectancy receive the highest quality care from the most appropriate professionals. As the field of nephrology shifts from an exclusive focus on increasing life expectancy to one paying greater attention to quality of life, this concept analysis offers an opportunity to make recommendations for appropriate use of language in a newly developing area.

Our service has been given the title Supportive Care Service after consultation with the local Patient Kidney Association (KPA). Options considered were Renal Palliative Care Service, Renal Conservative Management Service and Renal Supportive Care Service. Unequivocally, patients from the KPA opted for the latter, stating that the term 'palliative care' was unsuitable as it intimated that death was imminent and 'conservative management' was poorly understood. This emphasizes the importance of the contextual meaning of language used in practice and thus the need for a concept analysis in this area.

\section{The concept analysis}

\section{Aim}

The aim of the concept analysis was to clarify the meaning of the term 'renal supportive care'.

\section{Concept analysis method}

Renal supportive care was examined using Rodgers' (1989, 2000) evolutionary method (Table 1). This is a useful framework as it offers an inductive approach based on the idea that concepts are constantly modifying and changing. As knowledge and understanding is socially constructed and evolves as people engage with and learn from each other, the way we think about concepts in the past, present and the future is likely to alter. It is important, therefore, to capture the way a concept is currently being articulated in relation to the phenomena associated with it. Identifying

Table 1 Evolutionary concept analysis processes (based on Rodgers 1989, 2000)

Identify concept and associated vocabulary including surrogate terms Identify and select appropriate setting and sample for data collection Collect data to identify the attributes of the concept and the contextual basis of the concept including antecedents

Analyse data in reference to the characteristics of the concept mentioned above

Identify inferences, theories and implications for future development of the concept 
differences and similarities between related concepts is useful as it can enhance understanding of the concept itself, as well as ensuring that related practice is more explicit.

\section{Search methods}

Published papers concerning renal supportive care were collated in September 2006 from a review of databases including CINAHL (1982-2006), Medline (1950-2006), PsycINFO (1806-2006), British Nursing Index (19852006), International Bibliography of the Social Sciences (1951-2006) and ASSIA (1987-2006) using the phrase 'renal supportive care'. As this revealed no papers, 'renal' and 'supportive care' were entered. Papers written in English were considered. This search yielded 275 records and all titles and abstracts were read. The majority referred to active treatment measures for patients with renal failure, often acute renal failure, where supportive measures were employed in the short term whilst patients made a recovery. Only papers that added to the conceptual understanding of the term 'renal supportive care' were ultimately selected. This yielded only four records (Table 2). It was decided to add the term 'palliative care' to the search; however, this yielded only three records, two of which were duplicates and a third one was not considered relevant (Gridelli 2004).

Additional sources such as publications by the World Health Organisation (2004), the National Council for Palliative Care (NCPC 2001) and the Department of Health (DOH 2001, 2005) were included to gain further perspective on the concept.

The World Wide Web was also searched in English using the keyword renal supportive care, which yielded 1,360,000 'hits'. A rapid on-screen review of initial sources was undertaken to exclude those that did not correlate directly to the nature, practice or development of renal supportive care. Unfortunately many results were repeats, for example a book by Chambers et al. (2004), 'Supportive Care of the Renal Patient', was referred to in 11 of the first 30 hits. Several chapters of this book were used to inform this concept analysis. Other duplicate sources were identified and disregarded. By the seventh page (70th hit) no new sources were found (Table 2).

\section{Data analysis}

The sources obtained were examined and the content reviewed using the following key headings: definition or attributes, antecedents, consequences, related concepts and surrogate terms (Rodgers 2000). Although there was little literature, it was felt important to continue with the
Table 2 Records retrieved related to 'renal' and 'supportive care' $(n=4)$

Fainsinger R.L., Davison S.N. \& Brenneis C. (2003) A supportive care model for dialysis patients. Palliative Medicine 17(1), 81-82

Germain M.J. \& Cohen L. (2001) Supportive care for patients with renal disease: time for action [comment]. American Journal of Kidney Diseases 38(4), 884-886

Levy J.B., Chambers E.J. \& Brown E.A. (2004) Supportive care for the renal patient. Nephrology Dialysis Transplantation 19(6), 1357-1360

Noble H., Chesser A. \& Kelly D. (2005) The cessation of dialysis in patients with end-stage renal disease: developing an appropriate evidence base for practice. EDTNA/ERCA Journal 31(4), 208-211

References from World Wide Web $(n=6)$

Chambers J., Germain M. \& Brown E. (2004) Supportive Care for the Renal Patient. Oxford University Press, Oxford. Retrieved from http://www.oup.com/uk/catalogue/?ci=9780198516163. NHS Modernisation Initiative (2006) Supportive Care. NHS Modernisation Initiative. Retrieved from http://www.mykidney. org.uk/what_we_do/supportive_care on 29 September 2006 Royal Society of Medicine (2005) Journal of the Royal Society of Medicine. Supportive Care for the Renal Patient. Woolfson; 98:

132. Retrieved from http://www.jrsm.org/cgi/content/full/98/3/132 Jacobs C. (2005) Supportive Care for the Renal Patient. Volume 1. Nephrology Dialysis Transplantation, 20(6), 1280. Retrieved from http://ndt.oxfordjournals.org/cgi/content/full/20/6/1280

Robert Wood Johnson Foundation (2006) End Stage Renal Disease Workgroup in End-of-Life Care. Retrieved from http://www. promotingexcellence.org/i4a/pages/Index.cfm?pageID=3689 National Kidney Foundation (2006) Discontinuing treatment: key issues and ethical dilemmas. Chambers J. Retrieved from http://www.kidney.org.uk/Medical-Info/other/discontinuingtreatment.html

concept analysis and not expand the search to supportive care as an isolated keyword as this would undoubtedly open the search to include other chronic diseases such as cancer and this did not fit with our aim. Within the renal arena, technical aspects of care often supersede individual patients' holistic needs and we considered that there was a need to guide development of renal services towards a more holistic approach. By carrying out this concept analysis at this early stage in the development of our service, it was hoped that this debate could be further encouraged.

Analysis of the literature was inductive and themes were identified using a content analysis approach (Weber 1990). All data recorded under the definition headings were gathered together to identify the key attributes of the concept renal supportive care. Sources were grouped into key illuminative themes, which are now described below. 


\section{Results}

\section{Key attributes of renal supportive care}

Available from diagnosis to death, with an emphasis on honesty about prognosis and the impact of advanced renal disease

The literature discusses the need for supportive care to be available to patients with ESRD from diagnosis to death, stating that this is integral to a 'good death' (Holley 2004). This is similar to the goals of supportive care in the cancer arena, the difference being that some patients with cancer will make a recovery; this is different from those with renal failure, many of whom will inevitably die from their disease. Unlike in cancer care, renal specialists have tended to avoid this fact and to focus more on the scientific aspects of renal disease and its technical treatments. This is evident in the dearth of literature related to the care and experience of dying renal patients. Alongside this, changes in demographics and clinical profiles of renal patients are occurring, in conjunction with medical and ethical dilemmas associated with long-term dialysis of patients without the likelihood of a definitive cure. Patients are treated with expensive interventions and this has led to the need for new approaches. It is claimed that that open communication is required in dialysis units so that patients are not dialysed inappropriately and are encouraged and assisted to be involved in decision-making: 'The option of not having dialysis must be an explicit part of this discussion' (Levy et al. 2004, p. 4).

Some patients also need to understand that their prognosis may be limited and that dialysis may not be beneficial in terms of quality and length of life (Germain \& Cohen 2001). It has become clear that dialysis and transplantation may be associated with significant morbidity, meaning that patients are living with a life-limiting condition. Beyond extending the length of life, the idea of optimizing quality of life through supportive care is closely integrated with 'technical care' and is emerging as a priority in the management of patients with ESRD (Levy et al. 2004, Jacobs 2005).

\section{Interdisciplinary approach to care}

An integrated model of supportive care usually emphasizes an interdisciplinary team approach (Gokal 2004, Reiter \& Chambers 2004, Noble et al. 2005). However, there are differences in the way in which nephrology and hospice or palliative care teams function. The nephrology team usually address medical, psychosocial and existential problems associated with renal disease and dialysis treatment. Within the supportive care model, however, nephrology staff educated in palliative care philosophies might be encouraged to involve psychologists or palliative care teams to complement the care offered (Reiter \& Chambers 2004). However, this will call for a change in the culture of the renal unit, which in the past has often been self-contained and self-managing. The literature mentions the importance of the renal multidisciplinary team, but an interdisciplinary approach going beyond the renal team is becoming more important. In the past, supportive and palliative care have not been offered as treatment options. As staff are now focusing on the needs of those opting not to dialyse, their expertise is growing in tandem with increased communication with colleagues across other disciplines, e.g. palliative care and mental health. Keeping in mind the life-limiting effects of renal disease, there will be a focus on decision-making and end-of-life care, but consideration should also be given to how patients can live their lives to the optimum, with social and psychological support from the interdisciplinary team as required (Chambers et al. 2004).

\section{Restorative care}

A broader construction of renal supportive care is evolving that embraces both restorative and curative care: 'Restorative care is disease-specific therapy that seeks to reverse, halt or minimize the underlying pathophysiological processes of disease' (Reiter \& Chambers 2004, p. 16). Alongside palliative care, supportive care can maximize disease control and quality of life (Reiter \& Chambers 2004, Noble et al. 2005, Holley 2006). This brings together the unique challenges in renal supportive care in applying dialysis technology appropriately in tandem with the goals of individuals and their carers. In this model of supportive care a continuous overlap of restorative care and palliative care is envisaged, seeking to minimize the toxicity of treatment, the symptoms associated with renal disease and its co-morbidities.

\section{Family and carer support}

Support for carers is essential in renal supportive care situations (Levy et al. 2004, Reiter \& Chambers 2004). Those caring for patients with a chronic, terminal illness face a number of problems, such as fears of the unknown, of losing a loved one and of the level of care required (such as medication regimens), alongside anxiety and reduced status related to a loss of employment and income. There is also the knowledge that without dialysis treatment the patient will die (Reiter \& Chambers 2004), almost certainly within weeks. This means that patients will often continue with treatment whilst suffering debilitating side-effects such as fluid overload, fatigue and depression (Saini et al. 2006). Families live through this trauma with their loved ones and require psychological and spiritual support. Unfortunately, due to 
financial pressures, in many hospitals supportive care may often be lacking, as there is a tendency to focus on the patient. Similarly, family members may not attend dialysis sessions with the patient due to financial pressures. As renal supportive care services evolve the support required for carers of those with ESRD continues to be a priority (DOH 2005; Arnold \& Solomon 2006; NHS Modernisation Initiative 2006). How this can be more effectively managed at a time of great financial difficulty for healthcare services is unclear.

\section{Effective, lucid communication to ensure informed decision- making}

Achieving the goals of supportive care is not considered possible without effective, clear channels of communication (National Kidney Foundation 2006). Importantly, supportive care in advanced renal disease contexts when patients are clearly deteriorating requires patients and the multidisciplinary team, along with carers, to establish open dialogue about treatment options, advance planning, prognosis and preferred place of death (Cohen et al. 2001, Fainsinger et al. 2003, Holley 2006), as well as the promotion of shared decision-making (Levy et al. 2004, Reiter \& Chambers 2004). When reviewing treatment options there is a balance to be achieved between the potential of the treatment offered and its associated side-effects (Robert Wood Johnson Foundation 2003; National Kidney Foundation 2006). In ESRD, treatment has the potential to extend life at a cost in terms of morbidity that may initially be uncertain but in the long term is often experienced as severe.

\section{Associated vocabulary, including surrogate terms}

Conceptual confusion has arisen, with a number of terms being used interchangeably in the literature, such as supportive care, palliative care, end-of-life care, terminal care and more specific to nephrology, conservative management. Historically in the UK, palliative care services have focussed almost exclusively on the end-of-life phase, with cancer and palliative care services associated with terminal care. As palliative care has developed there has been a shift from using the phrase 'terminal care' towards symptom control and living with advanced disease. The terms palliative medicine and specialist palliative care are also used intermittently alongside end-of-life care, leading to even further confusion in the usage and application of terms (Clark \& Seymour 1999). NCPC (1995) defined terminal care as an important part of palliative care and as something that should be offered when no curative treatment was available and death could be expected within 12 months. However, it is often difficult to predict the moment of transition from palliative to terminal care within the trajectory of chronic diseases (Skilbeck 2005). Criticism of the term terminal care has also been made by Doyle et al. (1993), who points out that the word terminal is negative and suggests that nothing more can be done.

\section{Concept analyses of palliative care}

A concept analysis of palliative care (Meghani 2004) aimed at tracing the evolution of palliative care in the United States of America (USA) drew comparisons with related concepts such as hospice care and terminal care. Meghani (2004) states that important evolution in the understanding of palliative care has resulted in the emergence of new models of palliative care and concludes that palliative care has evolved to include populations who are not necessarily dying, 'but for whom alleviation of suffering and improvement of quality of life may be relevant goals' (p. 153). She identifies four attributes of palliative care - total active and individualized patient care, support for the family, interdisciplinary teamwork and effective communication - which appear central tenets of what might be considered essential nursing care. She makes the suggestion that each will 'depend upon the commitment of health professionals to recognize and integrate the changing concept of palliative care into everyday practice' ( $p$. 153). However, the question then arises as to why there is even a need for another concept such as palliative care when essential, quality care will do.

Seymour (2004) identifies a number of concepts that have been used to define palliative care nursing, including teamwork, dignity, comfort, empathy, hope, suffering and quality of life. She goes on to discuss in more depth the concept of caring, which she says 'is perhaps the fundamental element of palliative care nursing' (Seymour 2004, p. 57). It would appear that this view of palliative care has its early historical background in the idea that it was specifically for those who were dying, predominantly from cancer, that special skills were required to care for these dying patients and that these differed from those needed for other groups of patients.

\section{Emergence of supportive care}

Although the early hospice movement in the UK was mainly concerned with caring for those dying with cancer, subsequent developments have sought to extend services to others (Payne et al. 2004). Current policies in the UK encourage the introduction of palliative care earlier in the illness trajectory (National Institute for Clinical Excellence 2003). As this change in direction has taken place, the relatively recent term 'supportive care' has emerged; this was originally an accepted phrase in the context of care provided in addition to curative treatments for cancer patients (DOH 2000). More recently supportive care has been described as care that: 
helps the patient and their family to cope with the illness and treatment of it - from prediagnosis, through the process of diagnosis and treatment to cure, continuing illness or death and into bereavement. It helps the patient to maximize the benefits of treatment and to live as well as possible with the effects of the disease. It is given equal priority alongside diagnosis and treatment'. (NCPC 2002, p. 3)

The key elements of supportive care in cancer services have been derived from evidence about what it is that people with cancer want, including clear information and to be treated with dignity and respect (Seymour et al. 2005). The same attention has not been applied in the renal arena, and little is known about the end-of-life requirements of patients with renal failure.

\section{End-of-life care}

End-of-life care is a broad term that seems to identify more than the phase immediately before death. It has been referred to as the last year of life, although this can only be determined retrospectively (Seymour et al. 2001). In the UK, the term has been used by the Department of Health in the National Service Framework for Older People (DOH 2001) but, as stated by Seymour et al. (2005), a clear definition is not evident. The term end-of-life care, therefore, is most useful when death can be predicted with some degree of accuracy.

\section{Conservative management}

The term 'conservative management' has been used in the renal field to denote care offered to patients who have decided not to have dialysis (Burns 2006). It has also been referred to as 'supportive therapy' (Burns 2006). Most of these patients may be older, with co-morbidities, and it has been observed that some may benefit by declining dialysis particularly in terms of length and quality of survival (Smith et al. 2003) - although the evidence for this is scarce. Conservative management involves optimizing care for those who have made the decision not to embark on dialysis, and has also been termed 'maximum conservative management' by at least one author (Burns 2006). Although it is accepted that many patients on a conservative management pathway will ultimately die, some actually survive for considerable lengths of time and cannot be said to be in the dying phase at the time of referral. Little data are available at present to support this, however, which once again highlights the new and changing aspects of practice with which we are dealing. This situation has also led to difficulty in determining when renal patients require palliative care or to where they should be referred, as often 'conservative care' is all that is on offer.

\section{Antecedents and consequences of renal supportive care}

Antecedents are phenomena that precede a concept (Rodgers 2000). The antecedent to renal supportive care is the diagnosis of life-threatening renal failure, which leads to physical or psychological distress to the patient.

The consequences of a concept are the phenomena that are expected to follow its adoption or action (Rodgers 1989). In the literature it is argued that renal supportive care encourages shared decision-making from the point of diagnosis of renal failure until the end phase of life (Reiter \& Chambers 2004, Holley 2006). Adoption of the concept of renal supportive care has implications for patients and carers that may include high quality palliative care. It may also help to counter the denial of death that is often found in patients with ESRD, their carers and staff who care for them (Cohen et al. 2001, 2004).

\section{Discussion}

Integration of the principles and values of palliative care has been taking place in nephrology for over a decade. Led by physicians from the USA, who have established guidelines, the principles are intended to help clinicians involved in decisions about withholding and withdrawing from lifesupporting dialysis treatment (Poppel et al. 2003). Less widespread detailed guidelines are available in the UK, although the Renal Association recommended in 2003 that guidelines should be developed for palliative care of those patients who choose not to dialyse (Renal Association 2003). The NSF for Renal Services: Part 2 (DOH 2005) also includes a specific section on end-of-life care, as previously discussed. Unfortunately, the NSF gives very little guidance on what should be offered at the end of life.

In the healthcare literature as a whole, supportive care may be considered a general term that, to date, has been most closely associated with cancer patients (World Health Organisation 2004; Seymour et al. 2005, Skilbeck 2005). The literature search for this concept analysis failed to identify any reference to renal supportive care prior to 2001 (Germain \& Cohen 2001); however, the year 2004 brought the publication of the first textbook devoted to supportive care of renal patients (Chambers et al. 2004). It would appear that renal supportive care is now emerging from incorporating the ethos of palliative care to the care of renal patients on dialysis as a stand-alone concept.

Clarity is required if this concept is to be used appropriately and authors such as Levy et al. (2004) have attempted to achieve this. They state that a variety of symptoms might be present in patients with ESRD that, generally, are not well 
managed. As a result, they argue that a 'supportive care' approach to care should be adopted. This is not concerned solely with the end-of-life phase, but should be considered an adjunct to the management of patients at all stages of their renal illness.

In this emerging context, therefore, renal supportive care is not being presented as an alternative to dialysis, but rather as a philosophical underpinning of the interventions employed with the focus always on the individual patient. To this extent, renal supportive care has similarities to the goals of the palliative care movement but, within the technological focus of dialysis contexts, it may not equate to the withdrawal of all treatment.

This approach to renal supportive care as a philosophical value, focussing on decision-making and the promotion of life quality, shared openly between those involved, is also discussed by Levy et al. (2004), who emphasize the features necessary to achieve its aims (Table 3 ). It is interesting to note that the terms palliative care and conservative management are listed in this table, giving the impression of supportive care as the overarching concept. This becomes more interesting when probed further, as many of the points listed seem concerned with issues related to the end of life, such as discussions with hospices, debriefing for staff following the death of a patient, bereaved family support and an open culture towards discussing death. Perhaps moderating the terminology will enable renal practitioners to engage more readily with the problem that many renal patients face, namely inevitable early death.

Table 3 Examples of good practice in renal supportive care

Regular (weekly) multidisciplinary meetings including counsellors, psychologists, palliative care professionals

Joint renal-palliative care clinics

Joint education programmes with palliative care team

Preparative discussions and meetings with community services (e.g. hospices, district nurses) prior to need

Integration of nursing and psychological assessment notes into medical notes, or wide access database or electronic records

Identification of named key worker for each patient (either on dialysis or being managed conservatively)

Critical event debriefing of whole renal care team after a death

Easy availability of interpreters, and use of a small cohort who

become skilled in the necessary discussions

Encouragement of advanced directives

Open door policy for support for bereaved families

Development of an open culture discussing death, palliative care, supportive care during predialysis meetings with patients (singly or in groups)

Reproduced with permission of Oxford University Press from Levy et al. (2004) (http://www.oup.com).
Levy et al.'s (2004) work is especially useful as it has been developed by clinical practitioners. Unfortunately, the voices of patients and carers are missing from this work, which means that we cannot be sure that elements of renal supportive care are accurately depicted from their viewpoint.

In this analysis we have attempted to explicate the concept renal supportive care for the purpose of developing services that are presently evolving and to identify what the possible needs of service users might be. Ultimately, it should be possible to use an existing conceptual framework within which to set this work. As more research centred on the needs of renal patients and their carers is done, it may even be possible that a more useful theoretical basis can be identified. However, the results of this concept analysis may be useful in informing an interprofessional framework in the future.

\section{Inferences, theories and implications for future development of the concept}

Although it is established that an evolutionary process may add rigour to the process of concept analysis (Rodgers 1989), there are also some limitations to the present exercise. The sampling method may have excluded works that escaped the search system. Only work completed in English was considered, which might have excluded important work published in other languages.

This aside, this literature-based concept analysis demonstrates key features of renal supportive care. In common with much palliative care literature, renal supportive care emphasizes improved quality of life for both patients and their families, despite the inevitability of early death for some patients. Central to renal supportive care is the idea that helping patients to make informed decisions about dialysis treatments will not necessarily improve life expectancy or quality of life. This is where supportive care services will be needed. There is an emphasis on openness about the chronicity of renal disease, and the importance of recognizing and accepting the devastating impact of this illness on patients and carers.

More research related to renal supportive care and what it means to patients, families and professionals will be essential to ensure that, as the concept continues to evolve, it is adopted in an appropriate manner for those to whom it has most relevance. For instance, the overarching goal of integrating supportive care into the practice of renal dialysis and transplantation services from diagnosis onwards may have great benefit to patients. However, it will be important to clarify what patients and carers 


\section{What is already known about this topic}

- Appropriate models of supportive care need to be developed for non-cancer patient groups.

- Supportive care is a relatively new term in the field of nephrology.

- There is a need to differentiate between concepts such as supportive care, palliative care, end-of-life care and conservative management to allow their development in practice.

\section{What this paper adds}

- Specific features of renal supportive care include its relevance from the point of diagnosis onwards and its association with care delivered to patients who may choose not to start or to withdraw from dialysis.

- Renal supportive care encourages shared decisionmaking from the point of diagnosis of renal failure until the end phase of life.

- Central to renal supportive care is the belief that comfort and support is available to those with end-stage renal disease throughout their trajectory and is not only specific to symptom management and the end of life.

actually understand and expect from renal supportive care. By involving patients and their carers in the emergence of the concept, its relevance can be made clearer. There are important links to be made with the cancer arena, and it may be that there is scope for more renal nurses to develop expertise in renal supportive care. This might help to champion renal supportive care within a range of healthcare settings, as well as contributing to workforce development and education, patient experience and national policy.

The Renal Supportive Care Service established by the first author may be inappropriately named as it has targeted patients dying within 12 months. It might be more appropriately named a Renal Palliative Care Service to enable other disciplines to have a clearer understanding of the work involved. This aside, a small number of patients have outlived their prognosis, and it might be hasty to change the name until a clearer indication of patient trajectories to death are understood.

As further research into the needs of renal patients and their carers is undertaken in relation to renal supportive care, it is hoped that it will be possible to locate the findings within established conceptual frameworks or inform a new interprofessional framework.

\section{Conclusion}

The meanings associated with palliative and/or end-of-life care may have added to the expectation that supportive care is relevant only towards the end of life. This association may have diminished its perceived relevance at the time of diagnosis. Evidence exists that a combination of palliative and supportive care may be most appropriate over the course of progressive, life-limiting diseases such as renal failure. Importantly, elements of both may be initiated at any point in the disease trajectory (Fainsinger et al. 2003).

Renal supportive care may be considered a dynamic and emerging concept that is relevant, but not limited to, the endof-life phase of life (Levy et al. 2004). In its broadest sense it may also suggest a central philosophy underpinning renal service developments that allow patients, families and the multidisciplinary team time to work together, and with others across disciplines, to realize complex goals. In the future it needs to expand to encompass advance directives, in line with ethical and legal prerogatives. In this context, renal supportive care may be seen as a core aspect of renal nursing and the vehicle for the promotion of holistic care in any setting where renal patients are found - such as nursing homes and intensive care units. This will require the concept to be translated into a comprehensible and transparent reality, which can be easily explained to patients and their carers.

Undoubtedly, renal supportive care will change (as palliative care already has) over time as better understanding of disease processes occurs and continued evaluation establishes how the quality of people's lives may be improved further. Important aims at present include questioning and communicating the essential nature of the concept to practitioners, patients and their families. There is also a need for clarity about practice in renal units internationally, as most of the work in this area has emerged from the UK and the USA.

\section{Author contributions}

HRN were responsible for the study conception and design and the drafting of the manuscript. HRN performed the data collection and data analysis. DK, KRA and JM made critical revisions to the paper.

\section{References}

Ansell D., Feest T., Ahmad A. \& Rao R. (2005) UK Renal Registry Report 2004. UK Renal Registry, Bristol. 
Arnold R.M. \& Solomon L. (2006) Editorial: Renal palliative care: supporting our colleagues, patients and family. Journal of Palliative Medicine 9(4), 975-976.

Ashby M., op't H.C., Kellehear A., Kerr P.G., Brooks D., Nicholls K. \& Forrest M. (2005) Renal dialysis abatement: lessons from a social study. Palliative Medicine 19(5), 389-396.

Burns A. (2006) So what does 'conservative care' for renal patients really mean? Kidney Life (Autumn issue), 10-11.

Chambers J., Germain M.J. \& Brown E. (2004) Supportive Care for the Renal Patient. Oxford University Press, Oxford.

Clark D. \& Seymour J. (1999) Reflections on Palliative Care. Open University Press, London.

Cohen L.M., Poppel D.M., Cohn G.M. \& Reiter G.S. (2001) A very good death: measuring quality of dying in end-stage renal disease. Journal of Palliative Medicine 4(2), 167-172.

Cohen L.M. \& Germain M.J.(2004) Measuring quality of dying in end-stage renal disease. Seminars in Dialysis 17(5), 376-379.

Cohen L., Moss A., Weisbord S.D. \& Germain M. (2006) Renal palliative care. Journal of Palliative Care 9(4), 977-992.

DOH (2000) The NHS Cancer Plan: A Plan for Investment, A Plan for Reform. HMSO, London.

DOH (2001) National Service Framework for Older People. Department of Health, London.

DOH (2005) National Service Framework for Renal Services: Part Two. The Stationery Office, London.

Doyle D., Doyle D., Hanks G.W.C. \& MacDonald N. (eds) (1993) Domiciliary Palliative Care. Oxford Textbook of Palliative Medicine, Oxford.

Fainsinger R.L., Davison S.N. \& Brenneis C. (2003) A supportive care model for dialysis patients. Palliative Medicine 17(1), 8182.

Germain M.J. \& Cohen L. (2001) Supportive care for patients with renal disease: time for action [comment]. American Journal of Kidney Diseases 38(4), 884-886.

Gokal R. (2004) Foreword. In Supportive Care for the Renal Patient. (Chambers JE, Germain M. \& Brown E., eds), Oxford University Press, Oxford, pp. v-vi.

Grassman A., Gioberge S., Moeller S. \& Brown G. (2005) Editorial Comment. ESRD patients in 2004: global overview of patient numbers, treatment modalities and associated trends. Nephrology Dialysis Transplantation 20(12), 2587-2593.

Gridelli C. (2004) Same old story? Do we need to modify our supportive care treatment of elderly cancer patients? Focus on antiemetics. Drugs and Aging 21(13), 825-832.

Holley J.L. (2004) Advance directives and advance care planning in patients with end-stage renal disease. In Supportive Care for the Renal Patient (Chambers JE, Germain M. \& Brown E., eds), Oxford University Press, Oxford, pp. 35-43.

Holley J.L.(2006) Palliative Care in End Stage Renal Disease. Retrieved from http://www.patients.uptodate.com/topic.asp?file= dialysis/34388\&title=Kidney+failure on 29 September 2006.

ISN and IFKF (2007) World Kidney Day. Retrieved from http:// www.worldkidneyday.org/pages/why.php on 7 March 2007.

Jacobs C. (2005) Supportive care for the renal patient. Volume 1. Nephrology Dialysis Transplantation 20(6), 1280.

Levy J., Chambers J. \& Brown E. (2004) Supportive care for the renal patient. Nephrology Dialysis Transplantation 19(6), 1357-1360.
Meghani S. (2004) A concept analysis of palliative care in the United States. Journal of Advanced Nursing 46(2), 152-161.

Murtagh F., Addington-Hall J., Donohue P. \& Higginson I.J. (2006) Symptom management in patients with established renal failure managed without dialysis. EDTNA/ERCA Journal 11(2), 93-98.

National Institute for Clinical Excellence (2003) Supportive and Palliative Care Guidance for Cancer. NICE, London.

National Kidney Foundation (2006) Discontinuing Treatment: Key Issues and Ethical Dilemmas. Retrieved from http://www. kidney.org.uk/Medical-Info/other/discontinuing-treatment.html on 29 September 2006.

NCPC (1995) Specialist Palliative Care: A Statement of Definitions. The National Council for Palliative Care (formerly The National Council for Hospice and Specialist Palliative Care Services), London.

NCPC (2001) What do we Mean by Palliative Care? The National Council for Palliative Care (formerly The National Council for Hospice and Specialist Palliative Care Services), London.

NCPC (2002) Definitions of Supportive and Palliative Care. The National Council for Palliative Care (formerly The National Council for Hospice and Specialist Palliative Care Services), London.

NHS Modernisation Initiative (2006) Supportive Care. NHS Modernisation Initiative. Retrieved from http://www.mykidney.org.uk/ what_we_do/supportive_care on 25 October 2006.

Noble H., Chesser A. \& Kelly D. (2005) The cessation of dialysis in patients with end-stage renal disease: developing an appropriate evidence base for practice. EDTNA/ERCA Journal 31(4), 208211.

Payne S., Seymour J. \& Ingleton C. (eds) (2004) Introduction. In Palliative Care Nursing. Principles and Evidence for Practice, Open University Press, Berkshire, p. 1.

Poppel D.M., Cohen L. \& Germain M. (2003) The Renal Palliative Care Initiative. Journal of Palliative Medicine 6(321), 326.

Reiter G. \& Chambers J. (2004) The concept of supportive care for the renal patient. In Supportive Care for the Renal Patient (Chambers J.E., Germain M. \& Brown E., eds), Oxford University Press, Oxford, pp. 15-26.

Renal Association (2003) Treatment of Patients with Renal Failure: Recommended Standards and Audit Measures. Renal Association and Royal College of Physicians, London.

Robert Wood Johnson Foundation (2003) ESRD work-group final report summary on end-of-life care: recommendations to the field. Nephrology Nursing Journal 30, 59-63.

Rodgers B. (1989) Concept analysis and the development of nursing knowledge: the evolutionary cycle. Journal of Advanced Nursing 14, 230-335.

Rodgers B. (2000) Concept analysis: an evolutionary view. In Concept Development in Nursing: Foundations, Technique and Applications, 2nd edn (Rodgers B. \& Knafl K., eds), W.B. Saunders Company, Philadelphia, pp. 77-102.

Saini T., Murtagh F., Dupont P., McKinnon P., Hatfield P. \& Saunders Y. (2006) Comparative pilot study of symptoms and quality of life in cancer patients and patients with end stage renal disease. Palliative Medicine 20, 631-636.

Seymour J. (2004) What's in a name? A concept analysis of key terms in palliative care nursing. In Palliative Care Nursing. Principles 
and Evidence for Practice (Payne S., Seymour J. \& Ingleton C., eds), Open University Press, Berkshire, pp. 55-74.

Seymour J., Clark D. \& Philip I. (2001) Palliative care and geriatric medicine: shared concerns, shared challenges. Palliative Medicine 15, 269-270.

Seymour J., Witherspoon R., Gott M., Ross H. \& Payne S. (2005) End-of-Life Care: Promoting Comfort, Choice and Well-Being for Older People. The Policy Press in Association with Help the Aged, Bristol.

Skilbeck J. (2005) End of life care: a discursive analysis of specialist palliative care nursing. Journal of Advanced Nursing 51(4), 324-325.
Smith C., Silva-Gane M., Chandra S., Warwicker P., Greenwood R. \& Farrington K. (2003) Choosing not to dialyse: evaluation of planned non-dialytic management in a cohort of patients with endstage renal failure. Nephron Clinical Practice 95(2), 917-930.

Weber R. (1990) Basic Content Analysis, 2nd edn. Sage Publications, Newbury Park, CA.

World Health Organisation (2004) Palliative Care: The Solid Facts. WHO, Geneva. 